\title{
Low Vision Aids-Is Our Service Cost Effective?
}

\author{
'GAWN G. McILWAINE, ${ }^{2}$ JOHN A. BELL, ${ }^{3}$ GORDON N. DUTTON
}

\begin{abstract}
Summary
A questionnaire and telephone survey was carried out on a Scottish population of patients with impaired vision, in order to ascertain the proportion of patients who gain benefit from Low Vision, Aids (LVA) and to determine the number of LVAs which are retained but unused. One third of the patients who answered the questionnaire never use their LVAs, and one half were not satisfied with the service provided. A cost analysis indicated that approximately $(\mathfrak{f})$ 8,000 worth of LVAs are neither used nor returned each year to a single LVA service. The patients' ages, diagnoses, and visual acuities were related to the compliance rate. It appears that increasing age and decreasing visual acuity may be factors which decrease compliance. However none of the factors analysed could be used as a reliable predictor of patient satisfaction or of eventual benefit. Other health services which provide intensive training in the use of LVAs reportedly achieve a higher level of compliance. We conclude that our present service could probably be improved by the employment of additional staff specifically trained to teach patients how to make best use of the LVAs provided.
\end{abstract}

Optical devices have long been used to augment both normal and subnormal vision. In the seventeenth century Kircher and Eschinardi developed a near vision telescope. However, prior to the twentieth century these devices were not in common use due to the low level of literacy and the prohibitive cost of hand-made lenses. ' LVAs are now commonly issued to patients with major visual handicap. Patient satisfaction with the service provided and the number of individuals who use them have only rarely been evaluated..$^{2,3,4}$

LVAs increase the magnification of the object of regard at the expense of decreasing both the field of view and reading speed. Illumination may also be provided to increase the contrast. Considerable manual dexterity and motivation are required on the part of the patient in order to gain the maximum benefit from a LVA.
The current criterion for success in the prescription of LVAs is usually the assessment of visual acuity in the somewhat rarefied and highly lit environment of the LVA clinic at the time the instruments are dispensed. ${ }^{2,3}$ Humphry et al. determined the proportion of people who used their LVAs at home and found that $77 \%$ of the LVAs issued were not used! Half of this group indicated that their vision had not been improved, and the other half stated that the LVAs were too difficult to use. ${ }^{+}$

Various authors have attempted to improve the efficacy of LVAs for patients who have lost central vision as a consequence of macular disease. Two methods have been advocated. Eccentric viewing, ${ }^{7}$ and the use of prisms. ${ }^{8}$ The fundamental principle of both these methods is to place the image on the part of the paracentral retina which provides optimal

From: ${ }^{1}$ Gartnavel General Hospital, Glasgow. ${ }^{2}$ King's College Hospital, London. ${ }^{3}$ Tennent Institute of Ophthalmology, Glasgow.

Correspondence to: Dr G McIlwaine, FRCS, FCOphth, Senior Registrar, Department of Ophthalmology, Gartnavel General Hospital, Glasgow G12 0NY. 
viewing. We have, however been unable to identify any publications which evaluate the long term efficacy of such strategies, (apart from a study from Sweden, where it was found not to be possible for a patient to learn the eccentric viewing technique by himself). ${ }^{5}$ The techniques of eccentric viewing have considerable potential but probably require many hours of training to be used to their full potential. Moreover, it is probable that only younger or highly motivated individuals will be amenable to such training.

The Glasgow Eye Infirmary (GEI) provides a regional service for the issue of LVAs. Patients are referred by ophthalmologists for assessment. The patients are refracted by an optometrist, and issued with a LVA on loan if it is thought that their visual function has been significantly improved. Unfortunately staffing levels preclude routine follow-up for all cases. However, patients are encouraged to return to the clinic if they have any problems with the use of the LVAs. They are also requested to return the LVA if they find it of no benefit.

We have conducted a questionnaire survey

Fig. 1 Questions asked in the survey

1/How often do you use the Glasgow Eye Infirmary aid? Please tick the most appropriate box.

$\mathrm{A} /$ Used greater than 10 times per day $\mathrm{B} /$ Used between 5 and 10 times per day C/Used between 2 and 5 times per day

D/Used less than 2 times per day

E/Never used

2/Was the service provided at the Glasgow Eye Infirmary sufficient to meet your needs? Yes or No IF no would you like to see

A/Training in the use of the visual aid B/Follow up appointment to find if there are any problems

C/Other Service

(please specify)

3/Do you use a magnifying aid from elsewhere? Yes or No

4/How often do you use the magnifying aid from elsewhere. Please tick the most appropriate box.

A/Used greater than 10 times per day $\mathrm{B} /$ Used between 5 and 10 times per day

$\mathrm{C} /$ Used between 2 and 5 times per day

$\mathrm{D} /$ Used less than 2 times per day

E/Never used

Comments of patients who have been issued with LVAs in the Eye Infirmary, Glasgow, Scotland in order to determine the proportion of patients who are able to use the equipment issued and who are satisfied with the service provided. The proportion of unused equipment which was not returned was also determined.

\section{Patients and Methods}

One hundred patients who had attended the LVA clinic at the Glasgow Eye Infirmary in the year starting April 11988 were selected at random. Thirty four had attended during April 1988, 33 during November 1988 and 33 during March 1989. A. postal questionnaire survey was carried out. It was specifically designed to evaluate compliance and patient satisfaction with the service provided. It was typed in bold print and enlarged to the equivalent of $n 24$. The patients were encouraged to be as frank as possible with their comments and answers. The questions are listed in Figure 1. Questionnaires were concise in order to obtain a maximum response.

If there was no response, or if the questions were answered inappropriately the patient was followed up by means of a telephone call.

Each patient's age, sex, diagnosis and visual acuities were obtained from the LVA records. The ages of the group ranged from 13-92 years with an average of 70 years. There were 64 females and 36 males.

Statistical methods used were, Chi square $\mathrm{D}$ test for analysis of compliance rate and the Mann Whitney test for age distributions in the macular and non-macular groups.

\section{Results}

One hundred questionnaires were sent out. There was an initial response from 65 patients. After following up the remainder by means of a telephone call we obtained information from a further 26 patients. Eight patients could not be traced and one patient felt it was too soon to comment.

Of the 91 respondents who attended the LVA clinic 83 had been issued with LVAs. Fifty four of these patients were female and 29 were male. Forty five patients had macular disease and 17 had a single cause of poor vision which did not involve the macula. Twenty patients had multiple reasons for 
impaired vision. The diagnosis was not available in one patient. The mean age of the macular disease group was 74 years and the mean age of the non-macular group was 61 years. The Mann Whitney test for non parametric data showed there to be no significant difference in age between these two groups.

One hundred and twenty two LVAs were issued $64(53 \%)$ were hand held, $34(28 \%)$ spectacle mounted and $22(19 \%)$ stand magnifiers, high addition readers were excluded from analysis. Seventy four $(89 \%)$ patients were issued with LVAs to assist near vision, three $(4 \%)$ patients were issued with distance LVAs and six (7\%) were issued with both distance and near LVAs, because of the small number in the latter two groups no meaningful analysis could be obtained comparing near LVAs with distance LVAs. Twenty-one patients had also obtained LVAs elsewhere. The useage rate in patients who were issued with different types of LVAs was also assessed, the patients who were issued with multiple types of LVAs were grouped together, the results are shown in Table II.

Of the 83 patients issued with LVAs, 27 stated that they never used them (Figure 1, question 1). Three groups of approximately equal numbers of patients were analysed, their LVA appointments had been one month, six months and one year before the questionnaire was issued. No statistically significant differences were found in the useage rate in these three groups of patients, they were therefore grouped together for the purpose of analysis.

We attempted to determine the frequency of daily use of the LVAs issued from the GEI and the 21 elsewhere. The results are shown in Table II. There does not appear to be a relationship between age and daily use rate. However, the frequency of use does not necessarily reflect the economic and social benefit gained from the LVA prescribed.

Table I Useage rate of LVAs and age

\begin{tabular}{lcccc}
\hline $\begin{array}{l}\text { Times } \\
\text { per day }\end{array}$ & GEI LVA & $\begin{array}{c}\text { aid } \\
\text { (years) }\end{array}$ & $\begin{array}{c}\text { Mean age } \\
\text { elsewhere }\end{array}$ & $\begin{array}{c}\text { LVA from } \\
\text { (years) }\end{array}$ \\
\hline$>10$ & $15(18 \%)$ & 70 & $5(24 \%)$ & 67 \\
$5-10$ & $13(16 \%)$ & 68 & $4(19 \%)$ & 40 \\
$2-5$ & $16(19 \%)$ & 61 & $6(29 \%)$ & 71 \\
$<2$ & $12(14 \%)$ & 68 & $4(19 \%)$ & 36 \\
Never & $27(33 \%)$ & 74 & $2(9 \%)$ & 81 \\
\hline
\end{tabular}

Twenty one patients had obtained LVAs from elsewhere, 12 by self purchase, six from other clinics and three failed to specify where they had obtained the LVA, of these patients, two were not issued with an aid when attending the Glasgow Eye Infirmary because when assessed no benefit was anticipated, both patients used their aid more often than twice per day. It should be noted from Table II that only two out of 21 patients never used the LVA which they had obtained elsewhere, in contrast to the one third non-usage rate for the LVAs issued from the Glasgow Eye Infirmary.

Of those patients less than 65 years of age, 15 used their LVAs and three did not, whereas for those over 65 years of age 41 used them and 24 did not $(0.1<\mathrm{P}<0.2)$. For the 'macular group' 31 used their LVAs and 14 did not, whilst for the 'non-macular group' 10 used their LVAs and seven did not $(0.2<\mathrm{P}<0.5)$. Twenty-one males used their LVAs and eight did not, 35 females used their LVAs and 18 did not $(0.2<\mathrm{P}<0.5)$. Of the patients with visual acuities of $6 / 60$ or better, 42 used their LVAs and 17 did not, and for the patients with visual acuities worse than $6 / 6013$ used their LVAs and eight did not $(0.2<\mathrm{P}<0.5)$.

Forty-one patients were not satisfied with the service provided; 19 wanted follow-up appointments and 10 requested more training in the use of their LVA. Twelve patients who expressed dissatisfaction did not specify how they felt the service could be improved. Five patients commented that the LVAs were too heavy for prolonged use.

A cost analysis revealed the average cost of LVAs issued per patient to be £38. In the year during which the survey was performed 744 patients had been issued with LVAs. The extrapolated cost for the year is $£ 28,260$. Nineteen of the 27 non-users were contacted by telephone (eight could not be contacted

Table II Useage rate of different type of LVAs

\begin{tabular}{lrlrr}
\hline $\begin{array}{l}\text { Times } \\
\text { per day }\end{array}$ & $\begin{array}{c}\text { Hand held } \\
\text { magnifier }\end{array}$ & $\begin{array}{c}\text { Spectacle } \\
\text { magnifier }\end{array}$ & $\begin{array}{c}\text { Stand } \\
\text { magnifier }\end{array}$ & $\begin{array}{c}\text { Multiple } \\
\text { magnifiers }\end{array}$ \\
\hline$>10$ & $5(15 \%)$ & $2(15 \%)$ & $2(18 \%)$ & $6(23 \%)$ \\
$5-10$ & $4(12 \%)$ & $2(15 \%)$ & $3(27 \%)$ & $4(15 \%)$ \\
$2-5$ & $10(31 \%)$ & $2(15 \%)$ & $1(9 \%)$ & $3(12 \%)$ \\
$<2$ & $6(18 \%)$ & $1(8 \%)$ & $1(9 \%)$ & $2(8 \%)$ \\
Never & $8(24 \%)$ & $6(47 \%)$ & $4(37 \%)$ & $11(42 \%)$ \\
\hline
\end{tabular}


this way) only two patients had returned them. Interpolation of the estimated total cost per year indicates that approximately $£ 8,000$ of LVAs are neither used nor returned.

\section{Discussion}

The use of a questionnaire survey for people with poor sight is likely to have a low response rate. Although we used large print for our questionnaire we thought it likely that some patients would be unable to read our correspondence. To our knowledge the present questionnaire study is the only one to pursue the non-responders by telephone and consequently we have obtained completed information in 91 patients $(91 \%)$.

This study indicates that one third of LVAs issued from the Glasgow Eye Infirmary are probably never used. Ninety per cent of this unused equipment will probably not be returned. Although our results did not reach statistical significance it is suggested that patients under the age of 65 years are more likely to use their LVAs than those patients over the age of 65 years. In the present study over one third of patients over the age of 65 never use their LVAs compared with only one sixth of patients under this age. The trend of an apparent disparity between these two age groups probably reflects the fact that patients under the age of 65 are more likely to be involved in gainful employment and therefore reading and close work are much more important to them. Younger individuals are also able to learn new practical techniques with greater facility. It seems that only $9 \%$ of LVAs from elsewhere are never used. The present study did not analyse the training methods used in issuing these LVAs however the higher useage rate in this group may merely reflect the higher motivation in a group of people who are prepared to obtain a LVA from another source.

When the useage rate was analysed for the different types of LVAs issued the numbers of patients in each group were very small and not surprisingly failed to reach statistical significance. No meaningful analysis can therefore be made of these figures.

In our study patients with non-macular disease tended to have a lower compliance rate than the patients with 'macular disease'.
This is at variance with the data presented by Humphrey et al. ${ }^{+}$There were however relatively small numbers in the non-macular group and this may reflect a chance finding since these results were again not found to be statistically significant.

Almost one third of the patients never used their LVAs, although this represents a higher level of usage than that reported by Humphry et al., the service could still, no doubt be improved. ${ }^{+}$

In Sweden the LVA clinic employs an ophthalmologist, an ophthalmic optician, a low vision teacher and an adaptation teacher who collaborate closely. A number of training sessions is given until the patients can use the aids to their advantage. A survey of the use of LVAs in Sweden showed that there was an almost $100 \%$ success rate (as judged by the patients) for individuals with moderate "macular degeneration'.5 In New Zealand patients are assessed by the optician and an occupational therapist. The occupational therapist then offers the patient a home visit if this is practicable. The patient is then reviewed after one month. By contrast a single appointment with an optometrist is the norm in many British LVA clinics.

In the Glasgow Eye Infirmary we estimate that approximately $£ 8,000$ worth of LVAs are neither used nor returned each year. It is likely that a cost analysis would reveal a similar loss of LVAs in other units. Moreover, it follows that approximately one third of the LVA consultations are to no avail.

In conclusion, in order to improve the quality of the LVA service additional patient follow-up and training in the use of LVAs is required for which the Swedish practice could be considered as a role model. The implications with regard to the additional staffing required, especially in the context of our aging population warrant further evaluation and planning.

With grateful thanks to Lorna Jack, Elaine Shepherd, Iain Ferguson and Elizabeth McLure for their advice and help in collecting the data and for typing the manuscript.

\footnotetext{
References

${ }^{1}$ Hertel E: Ueber Ersatz der operativen Korrektion hochgradiger Myopic durch eine glaeser Kombination (Fernrohrbrille). Albrecht v. Graefes Arch Ophthal 1910; 75: 586-604.
} 
${ }^{2}$ Temel A: Low Vision Aids (evaluation of 185 patients). Ophthal Physiol Opt 1989; 9: 327-31.

'Mancil GL and Nowakowski R: Evaluation of reading speed with four Low Vision Aids. Am J Optom Physiol Opt 1986; 63: 708-13.

${ }^{4}$ Humphry RC and Thompson GM: Low Vision Aids-Evaluation in a General Eye Department. Trans Ophthalmol Soc UK 1986, 105: 296-303.

${ }^{5}$ Nilsson UL and Nilsson SFG: Rehabilitation of the visually handicapped with advanced macular degeneration. Doc Ophthalmol 1986; 62: 345-67.
${ }^{6}$ Sanderson FG, Cumming AE, Polkingthorne PJ: A hospital rental system for Low Vision Aids. Aust NZ J Ophthalmology 1986; 14: 359-63.

${ }^{7}$ Goodrich GL and Mehr EB: Eccentric viewing training and low vision aids: Current practice and implications of peripheral retinal research. Am J Optom Physiol Opt 1986; 63: 119-26.

${ }^{8}$ Romayanda N, Wong S Elzeneiney IH, Chan GH: Prismatic scanning method for improving visual acuity in patients with low vision. Ophthalmology 1982; 89: 937-45. 